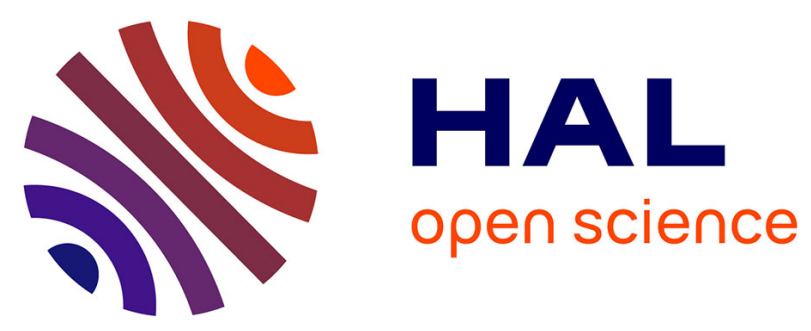

\title{
Theoretical-experimental evaluation of the photocatalytic activity of $\mathrm{KCa} 2 \mathrm{Ta} 3-\mathrm{xNbxO} 10$
}

Arnayra Brito, Valérie Bouquet, Valérie Demange, François Cheviré, Maryline

Guilloux-Viry, Thiago Marinho, Juliana K.D. Souza, Lais Lima, Nayara

Pinheiro, Ieda M.G. Santos, et al.

\section{To cite this version:}

Arnayra Brito, Valérie Bouquet, Valérie Demange, François Cheviré, Maryline Guilloux-Viry, et al.. Theoretical-experimental evaluation of the photocatalytic activity of KCa2Ta3-xNbxO10. Materials Letters, 2019, 253, pp.392-395. 10.1016/j.matlet.2019.07.006 . hal-02183907

\section{HAL Id: hal-02183907 https://hal-univ-rennes1.archives-ouvertes.fr/hal-02183907}

Submitted on 25 Sep 2019

HAL is a multi-disciplinary open access archive for the deposit and dissemination of scientific research documents, whether they are published or not. The documents may come from teaching and research institutions in France or abroad, or from public or private research centers.
L'archive ouverte pluridisciplinaire HAL, est destinée au dépôt et à la diffusion de documents scientifiques de niveau recherche, publiés ou non, émanant des établissements d'enseignement et de recherche français ou étrangers, des laboratoires publics ou privés. 


\title{
Theoretical-experimental evaluation of the photocatalytic activity of $\mathrm{KCa}_{2} \mathrm{Ta}_{3}$ -
} ${ }_{\mathrm{x}} \mathbf{N b}_{\mathrm{x}} \mathrm{O}_{10}$

Arnayra S. Brito ${ }^{1}$, Valerie Bouquet ${ }^{2}$, Valerie Demange ${ }^{2}$, François Cheviré ${ }^{2}$, Maryline Guilloux-Viry ${ }^{2}$, Thiago D. Marinho ${ }^{1}$, Juliana K.D. Souza ${ }^{1}$, Lais C. Lima ${ }^{1}$, Nayara A. Pinheiro $^{1}$, Ieda M.G. Santos ${ }^{1}$, Julio R. Sambrano ${ }^{3}$, Anderson R. Albuquerque ${ }^{4}$, Ary S. Maia $^{1 *}$.

${ }^{1}$ - NPE-LACOM - Federal University of Paraíba, 58051-900, João Pessoa, PB, Brazil

2 - Univ. Rennes, CNRS, ISCR - UMR 6226, ScanMat - UMS 2001, F-35000 Rennes, France

3 - Modeling and Molecular Simulation Group, INCTMN-UNESP, São Paulo State University, Bauru, SP, Brazil

4 - Chemistry Institute, Federal University of Rio Grande do Norte, 59078-970, Natal, RN, Brazil

\section{* Corresponding author:}

E-mail address: arymaia@quimica.ufpb.br

\begin{abstract}
:
$\mathrm{KCa}_{2} \mathrm{Ta}_{3-\mathrm{x}} \mathrm{Nb}_{\mathrm{x}} \mathrm{O}_{10}$ samples were synthesized by solid-state reaction and evaluated on the hydroxylation of terephthalic acid under UVC irradiation. Computational simulations via DFT were carried out in order to study their structural and electronic properties. Theoretical results show good agreement with experimental data, regarding lattice parameters and band-gap energy values and indicated that the photocatalytic performance for hydroxyl radicals production is directly related to the degree of octahedral distortions in these materials.
\end{abstract}

\section{Keywords:}

DFT; Dion-Jacobson perovskite; tantaloniobates; octahedra distortion

\section{Introduction:}

Dion-Jacobson-type (D-J) perovskites have drawn attention for their physical and chemical properties, particularly for their photocatalytic activity [1-4]. They have molecular formula $A_{x}\left[B_{m-1} M_{n} O_{3 n+1}\right]$ (where $A$ is an alkaline ion; $B$ an alkaline earth ion; $M$ a transition metal and $n$ indicates the number of $\left[\mathrm{MO}_{6}\right]$ octahedra that form each 
perovskite-like slab) [5]. Some authors relate the photocatalytic activity of perovskites to the degree of octahedron distortion [6-8]. The main objective of this work was to study tantaloniobates $\left(\mathrm{KCa}_{2} \mathrm{Ta}_{3-\mathrm{x}} \mathrm{Nb}_{\mathrm{x}} \mathrm{O}_{10} \mathrm{x}=0,1\right.$ and 2) with D-J perovskite structure and to evaluate the effect of $\mathrm{Ta}: \mathrm{Nb}$ ratio on their structural and photocatalytic properties.

\section{Experimental:}

Materials were synthesized by solid-state reaction using carbonates or oxides as precursors under temperatures between 1100 and $1200{ }^{\circ} \mathrm{C}$. Synthesized materials were characterized by X-ray diffraction (XRD, Bruker D8 Advance, CuKa1), Diffuse Reflectance Spectroscopy (DRS, Varian Cary 100 UV-Vis, 250-800 nm), Raman spectroscopy (Renishaw inVia Raman Microscope, 514 nm laser wavelength), SEMEDXS (Jeol JSM $7100 \mathrm{~F}$ microscope, operating at $10 \mathrm{kV}$ for Energy Dispersive X-ray Spectroscopy analyses (EDXS) using an Oxford Instruments AZtec system). Formation of hydroxyl radicals was evaluated by the photohydroxylation of terephthalic acid (TA), used as probe at room temperature [9], under conditions previously described in the literature [10]. A blank test was performed with TA solution irradiation without photocatalyst. Formation of the luminescent 2-hydroxyterephthalic acid (HTA) was evaluated by spectrofluorimetry (Shimadzu RF-5301PC). Further details of syntheses and characterizations are displayed in the Supplementary Data (SD-01).

\section{Computational details:}

Periodic DFT calculations were performed with CRYSTAL17 software [11] by using the global hybrid functional PBE0. $\mathrm{KCa}_{2} \mathrm{Ta}_{3} \mathrm{O}_{10}$ and $\mathrm{KCa}_{2} \mathrm{Nb}_{3} \mathrm{O}_{10}$ are layered perovskites with orthorhombic structures (C222 and $\mathrm{Cmcm}$ space groups respectively) and a slab constituted by the stacking of three corner-connected octahedra $\left[\mathrm{Nb} / \mathrm{TaO}_{6}\right]$. In the absence of information about $\mathrm{KCa}_{2} \mathrm{TaNb}_{2} \mathrm{O}_{10}$ and $\mathrm{KCa}_{2} \mathrm{Ta}_{2} \mathrm{NbO}_{10}$ symmetry space group and for purpose of comparison, all materials were calculated in the $\mathrm{KCa}_{2} \mathrm{Ta}_{3} \mathrm{O}_{10}$ (C222) space group. There are two distinct crystallographic positions for the transition metals, two equivalent octahedra (Oct1) constituting the slab edges while the other one (Oct2) forms the inner layer. For purposes of computational models depending on the chemical composition $\mathrm{Nb}$ and/or Ta were ascribed to either crystallographic positions without considering any mixed occupations. Band structure and density of states (DOS) calculations were plotted employing the same $k$-points set as the diagonalization of the Fock matrix for optimization process. Distortion index was based on bond lengths as 
proposed by Baur [12] and the effective coordination number was calculated as the sum of the so-called "bond weight" of all polyhedron bonds. Further details of computational simulations are displayed in Supplementary Data (SD-02).

\section{Results and Discussion:}

XRD patterns (Figure 1(1)) confirmed the formation of the targeted phases with small amount of $\mathrm{KNbO}_{3}$. Progressive substitution of tantalum by niobium atoms in the structure did not significantly modify the observed reflections except for small displacements of the peaks. $\mathrm{KCa}_{2} \mathrm{Ta}_{3} \mathrm{O}_{10}$ pattern was indexed by ICDD 01-089-8542, in agreement to literature [2]. No significant morphological changes were observed for the synthesized materials, as evidenced by SEM results (SD-03) and large surfaces assigned to $\left(\begin{array}{lll}0 & 1 & 0\end{array}\right)$ planes were observed [13]. Stoichiometry of the samples was confirmed by SEM-EDXS (Table 1).
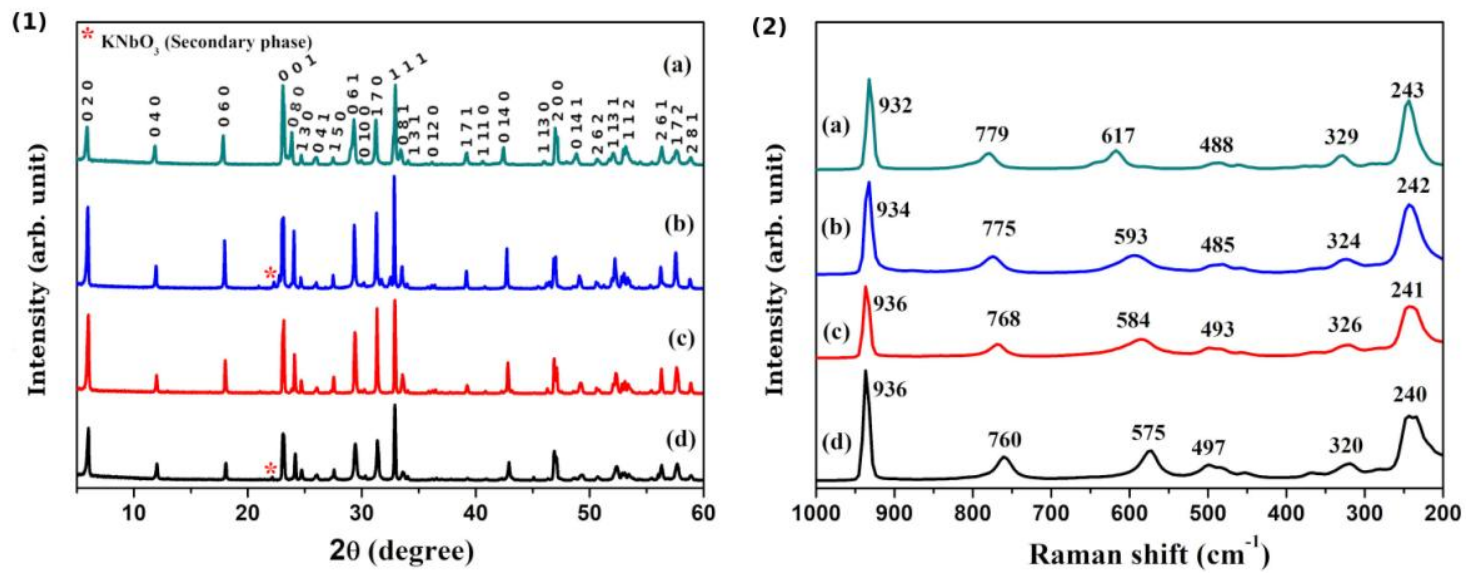

Figure 1 - XRD patterns (1) and Raman spectra (2) of $\mathrm{KCa}_{2} \mathrm{Ta}_{3} \mathrm{O}_{10}(\mathrm{a}), \mathrm{KCa}_{2} \mathrm{Ta}_{2} \mathrm{NbO}_{10}$ (b), $\mathrm{KCa}_{2} \mathrm{TaNb}_{2} \mathrm{O}_{10}$ (c), $\mathrm{KCa}_{2} \mathrm{Nb}_{3} \mathrm{O}_{10}(\mathrm{~d})$.

Table 1 - Experimental composition and band-gap energy $\left(E_{g}\right)$ of the synthesized materials compared to theoretical results.

\begin{tabular}{cccccccc}
\hline \multicolumn{3}{c}{ Experimental Results } & \multicolumn{3}{c}{ Theoretical Results } \\
\hline \multicolumn{1}{c}{ Samples } & Composition & $\mathrm{E}_{\mathrm{g}}(\mathrm{eV})$ & $a(\AA)$ & \multicolumn{2}{c}{$b(\AA)$} & $c(\AA)$ & $\mathrm{E}_{\mathrm{g}}(\mathrm{eV})$ \\
\hline $\mathrm{KCa}_{2} \mathrm{Ta}_{3} \mathrm{O}_{10}$ & $\mathrm{~K}_{0.8} \mathrm{Ca}_{2} \mathrm{Ta}_{2.9} \mathrm{O}_{10}$ & 4.2 & $3.9272(+1.59 \%) *$ & $28.533(-4.18 \%)^{*}$ & $3.8856(+0,87 \%) *$ & 4.29 \\
\hline $\mathrm{KCa}_{2} \mathrm{Ta}_{2} \mathrm{NbO}_{10} \mathrm{~K}_{1.1} \mathrm{Ca}_{2} \mathrm{Ta}_{2.1} \mathrm{Nb}_{0.8} \mathrm{O}_{10}$ & 3.8 & 3.9708 & 28.539 & 3.8810 & 3.68 \\
\hline $\mathrm{KCa}_{2} \mathrm{TaNb}_{2} \mathrm{O}_{10} \mathrm{~K}_{1.2} \mathrm{Ca}_{2} \mathrm{TaNb}_{1.9} \mathrm{O}_{10}$ & 3.6 & 3.9530 & 28.552 & 3.9161 & 3.46 \\
\hline $\mathrm{KCa}_{2} \mathrm{Nb}_{3} \mathrm{O}_{10}$ & $\mathrm{~K}_{1.2} \mathrm{Ca}_{2} \mathrm{Nb}_{2.8} \mathrm{O}_{10}$ & 3.5 & 3.9824 & 28.480 & 3.9169 & 3.41 \\
\hline
\end{tabular}

* Percent deviations from the lattice parameters of ICDD 01-089-8542. 
Raman spectra (Figure 1(2)) evidenced the existence of two different types of
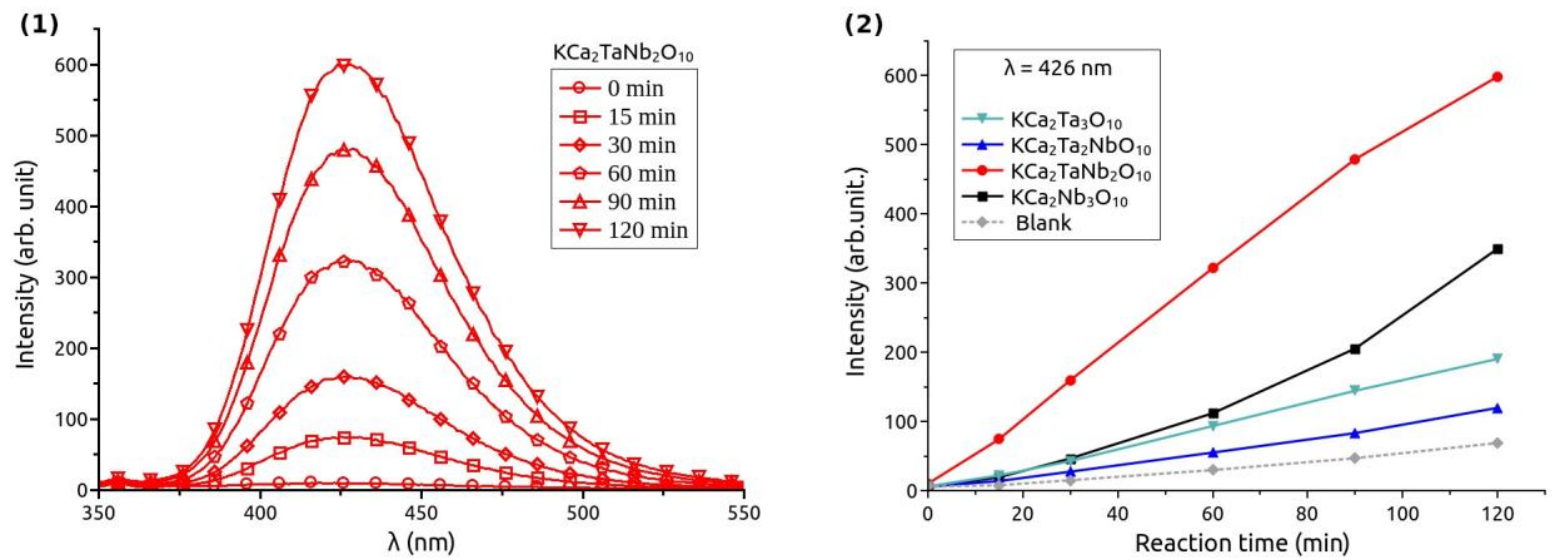

Figure 2 - Fluorescence spectra of HTA formed in the reaction catalyzed by $\mathrm{KCa}_{2} \mathrm{TaNb}_{2} \mathrm{O}_{10}$ (1). Maximum intensity of HTA fluorescence produced by photohydroxylation of TA as a function of reaction time (2).

In an attempt to better understand the photocatalytic results, computational simulations were carried out focusing on structural and electronic aspects of the $\mathrm{KCa}_{2} \mathrm{Ta}_{3-\mathrm{x}} \mathrm{Nb}_{\mathrm{x}} \mathrm{O}_{10}$ phases. Similar data were not found in the literature for these systems. Table 1 depicts the calculated cell parameters and the resulting deviations which were very low. Band structure (Figure SD-05) showed that all materials have indirect band- 
gap $(\mathrm{X}-\Gamma)$ and quite similar values were observed when comparing experimentally and patterns for all samples, suggested that the previously assumed space group was valid. The calculated atomic positions were used to construct the structures shown in Figure 3. Regardless the atom that occupied the octahedral site of the layer edge (Oct1), this octahedron presented greater distortion than the one in the inner layer (Oct2). However, when $\mathrm{Nb}$ occupied this site, with $\mathrm{Ta}$ in the central position $\left(\mathrm{KCa}_{2} \mathrm{TaNb}_{2} \mathrm{O}_{10}\right)$, the highest distortion index of these octahedra took place (Figure 3). This distortion was so pronounced that this $\mathrm{Nb}$ tended to 5 -fold coordination, due to the high value of the axial $\mathrm{Nb}-\mathrm{O}$ bond length, directed to the $\left[\mathrm{TaO}_{6}\right]$ octahedron. A tendency to increase tilting between octahedra along $a$ axis, culminating with a decrease of approximately $18^{\circ}$ in the $\mathrm{Nb}-\mathrm{O}-\mathrm{Nb}$ bond, can also be observed for $\mathrm{KCa}_{2} \mathrm{TaNb}_{2} \mathrm{O}_{10}$ (Figure SD-06).

A marked shift of the Fermi level towards the conduction band (CB) was also observed in the band structure (Figure SD-04), similar to Burstein-Moss shift [16], which indicates the need to expand the electronic evaluation of theoretical calculations. According to DOS (Figure SD-05) the valence band (VB) was mainly constituted by oxygen atoms, whereas the conduction band had greater participation of metal atoms. A detail of VB and CB edges is presented in Figure 3. 

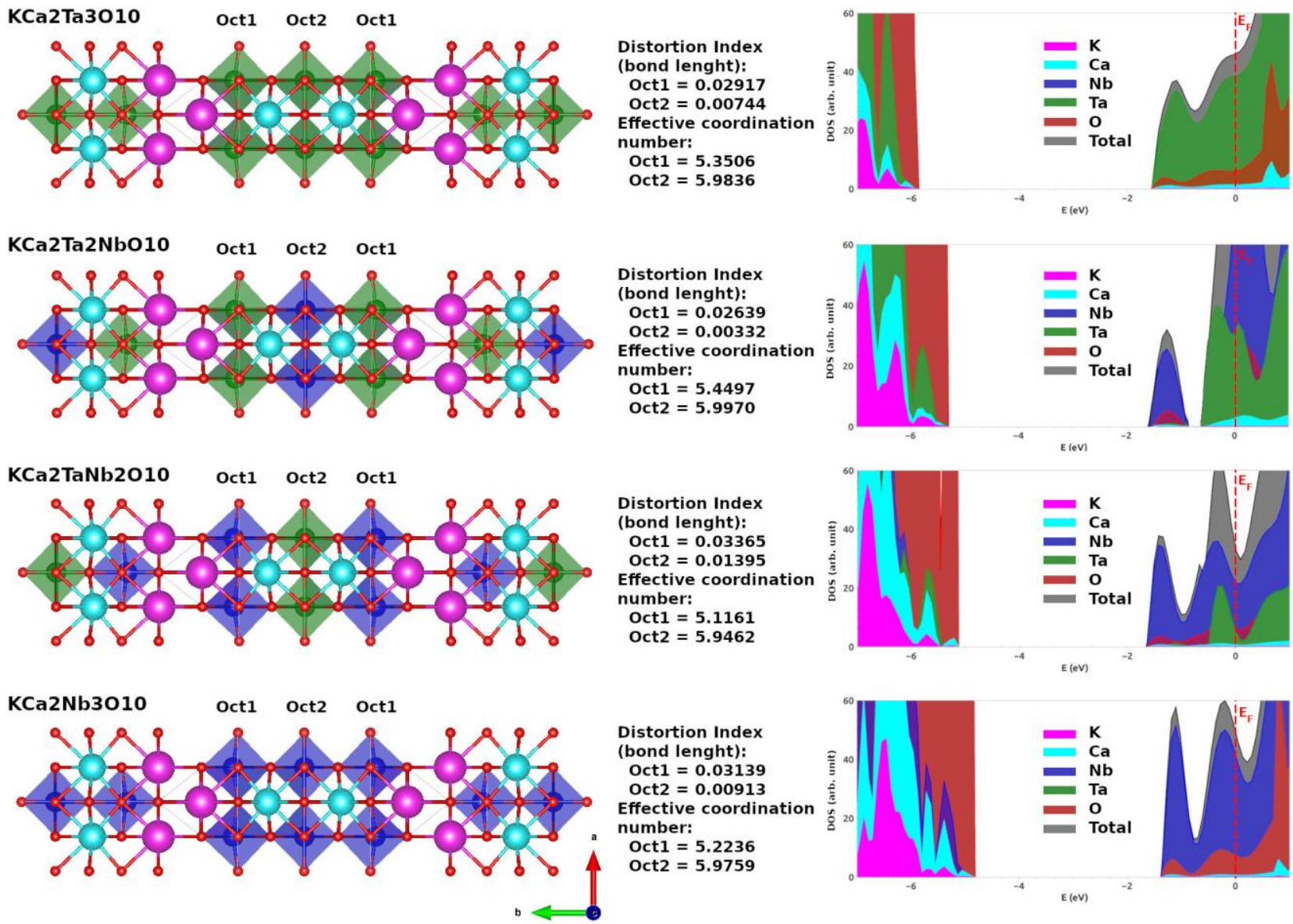

Figure 3 - Structural representation of the $\mathrm{KCa}_{2} \mathrm{Ta}_{3-\mathrm{x}} \mathrm{Nb}_{\mathrm{x}} \mathrm{O}_{10}$ phases, with octahedron

distortion index, $\mathrm{Nb} / \mathrm{Ta}$ effective coordination number and $\mathrm{DOS}$ results.

Due to its higher electronegativity, as usually assigned [8] 4d states of $\mathrm{Nb}$ lies lower than $5 \mathrm{~d}$ state of $\mathrm{Ta}$ and thus participates preponderantly to the $\mathrm{CB}$ edge for all $\mathrm{Nb}$ containing structures, regardless of its proportion or its location. A deepening of theoretical calculations regarding electronic effects is already underway and will be released soon in the form of a new theoretical article.

Correlating the experimental data of hydroxyl radicals photogeneration with theoretical calculations results, it is evident that the increasing order of photocatalytic activity is exactly the same for the octahedron distortion index in this triple-layered D-J perovskite. The evidence that the photocatalytic activity of these materials may be related to both the distortion index of the octahedra and the DOS of the CB is in agreement with the literature [6-8].

\section{Conclusion:}


Tantaloniobates with DJ perovskite structure were successfully synthesized by solid-state reaction. The $\left[\mathrm{MO}_{6}\right]$ octahedron distortion index and the composition of the $\mathrm{CB}$ edge determined by theoretical calculations showed a great dependence on the type of element that occupies the $M$ sites of the structure . Activity for hydroxyl radical photogeneration followed exactly the same increasing order of the octahedron distortion index, which is $\mathrm{KCa}_{2} \mathrm{Ta}_{2} \mathrm{NbO}_{10}<\mathrm{KCa}_{2} \mathrm{Ta}_{3} \mathrm{O}_{10}<\mathrm{KCa}_{2} \mathrm{Nb}_{3} \mathrm{O}_{10}<\mathrm{KCa}_{2} \mathrm{TaNb}_{2} \mathrm{O}_{10}$.

\section{Conflicts of Interest:}

None.

\section{Acknowledgments:}

This work was conducted during a visiting scholar period at Université de Rennes 1, sponsored by the Capes Foundation within the Ministry of Education, Brazil (grant $\mathrm{n}$. BEX 88881.132329/2016-01). The computational facilities were supported by resources supplied by Brazilian Funding Agencies FAPESP, CNPq and the Center for Scientific Computing of the São Paulo State University (Grid Unesp). SEM experiments were performed on CMEBA platform (ScanMAT unit, UMS 2001, University of Rennes 1CNRS).

\section{References:}

[1] X.Zong, L.Wang, Ion-exchangeable semiconductor materials for visible lightinduced photocatalysis, Journal of Photochemistry and Photobiology C: Photochemistry Reviews. 18 (2014) 32-49. https://doi.org/10.1016/j.jphotochemrev.2013.10.001.

[2] M.J.Geselbracht, H.K.White, J.M.Blaine, M.J.Diaz, J.L.Hubbs, N.Adelstein, J.A.Kurzman, New solid acids in the triple-layer Dion-Jacobson layered perovskite family, Materials Research Bulletin. 46, (2011) 398-406. https://doi.org/10.1016/j.materresbull.2010.12.007.

[3] D.Jiang, T.Wang, Q.Xu, D.Li, S.Meng, M.Chen, Perovskite oxide ultrathin nanosheets/g- $\mathrm{C}_{3} \mathrm{~N}_{4} 2 \mathrm{D}-2 \mathrm{D}$ heterojunction photocatalysts with significantly enhanced photocatalytic activity towards the photodegradation of tetracycline, Applied Catalysis B: Environmental 201 (2017) 617-628. http://dx.doi.org/10.1016/j.apcatb.2016.09.001 
[4] D.Jiang, W.Ma, Y.Yao, P.Xiao, B.Wen, D.Li, M.Chen, Dion-Jacobson-type perovskite $\mathrm{KCa}_{2} \mathrm{Ta}_{3} \mathrm{O}_{10}$ nanosheets hybridized with g-C3N4 nanosheets for photocatalytic $\mathrm{H}_{2}$ production, Catalysis Science \& Technology 8 (2018) 3767-3773. https://doi.org/10.1039/C8CY00930A.

[5] M.A.Bizeto, A.L.Shiguihara, V.R.L.Constantino, Layered niobate nanosheets: building blocks for advanced materials assembly, Journal of Materials Chemistry 19 (2009) 2512-2525. https://doi.org/10.1039/b821435b.

[6] J.Sato, H.Kobayashi, Y.Inoue, Photocatalytic Activity for Water Decomposition of Indates with Octahedrally Coordinated $\mathrm{d}^{10}$ Configuration. II. Roles of Geometric and Electronic Structures, The Journal of Physical Chemistry B 107 (2003) 7970-7975. https://doi.org/10.1021/jp030021q.

[7] K.Maeda, Photocatalytic water splitting using semiconductor particles: History and recent developments, Journal of Photochemistry and Photobiology C: Photochemistry Reviews 12 (2011) 237-268. https://doi.org/10.1016/j.jphotochemrev.2011.07.001.

[8] A.Kudo, Y.Miseki, Heterogeneous photocatalyst materials for water splitting, Chemical Society Reviews, 38 (2009) 253-278. https://doi.org/10.1039/b800489g

[9] Y.Jing, B.P.Chaplin, Mechanistic Study of the Validity of Using Hydroxyl Radical Probes to Characterize Electrochemical Advanced Oxidation Processes, Environmental Science \& Technology 51 (2017), 2355-2365. https://doi.org/10.1021/acs.est.6b05513.

[10] A.R.F.A.Teixeira, A.M.Neris, E.Longo, J.R.C.Filho, A.Hakki, D.Macphee, I.M.G.Santos, $\mathrm{SrSnO}_{3}$ perovskite obtained by the modified Pechini method-Insights about its photocatalytic activity, Journal of Photochemistry \& Photobiology A: Chemistry 369 (2019) 181-188. https://doi.org/10.1016/j.jphotochem.2018.10.028.

[11] R.Dovesi, A.Erba, R.Orlando, C.M.Zicovich-Wilson, B.Civalleri, L.Maschio, M.Rérat, S.Casassa, J.Baima, S.Salustro, B.Kirtman, Quantum-Mechanical Condensed Matter Simulations with CRYSTAL, WIREs Computational Molecular Science 8 (2018) e1360. https://doi.org/10.1002/wcms.1360. 
[12] W.H.Baur, The geometry of polyhedral distortions. Predictive relationships for the phosphate group, Acta Crystallographica Section B 30 (1974) 1195-1215. https://doi.org/10.1107/S0567740874004560.

[13] A.S.Maia, F.Cheviré, V.Demange, V.Bouquet, M.Pasturel, S.Députier, R.Lebullenger, M.Guilloux-Viry, F.Tessier, Preparation of niobium based oxynitride nanosheets by exfoliation of Ruddlesden-Popper phase precursor, Solid State Science 54 (2016) 17-21. https://doi.org/10.1016/j.solidstatesciences.2015.11.013.

[14] S.-H.Byeon, H.-J.NAM, Neutron Diffraction and FT-Raman Study of IonExchangeable Layered Titanates and Niobates, Chemistry of Materials 12 (2000) 17711778. https://doi.org/10.1021/cm9906506

[15] V.Džimbeg-Malčić, Ž.Barbarić-Mikočević, K.Itrić, Kubelka-Munk theory in describing optical properties of paper (I), Tehnički Vjesnik 18 (2011) 117-124. https://hrcak.srce.hr/65936.

[16] M.Burbano, D.O.Scanlon, G.W.Watson, Sources of Conductivity and Doping Limits in CdO from Hybrid Density Functional Theory, Journal of the American Chemical Society 38 (2011) 15065-15072. https://doi.org/10.1021/ja204639y 